\title{
Presentación Editorial
}

\section{Editorial Presentation}

En medio de la terrible crisis planetaria en que nos ha sumido la pandemia presentamos a nuestros lectores un nuevo fascículo de la revista Discusiones Filosóficas. Infortunadamente, la crisis no afecta únicamente la salud y las actividades ordinarias. Junto con el estado de anormalidad generalizado aparecen nuevas y constantes amenazas contra la ciencia y el importante rol de divulgación que desarrollan las revistas académicas. En comunidades vecinas como la otrora poderosa Brasil o el siempre admirado y tomado como ejemplo México, surgen voces de alerta y quejas sobre la desfinanciación creciente de la ciencia y la precarización de las revistas científicas así como sobre la desvalorización del trabajo de los editores, revisores y autores. En nuestro país ya se ha vuelto costumbre que en cada convocatoria de medición y clasificación de revistas, COLCIENCIAS introduzca nuevos requisitos y copie, de manera completamente acrítica e inconsulta, las normas y condiciones con las cuales se seleccionan y miden las revistas editadas por los grandes monopolios comerciales como Elsevier, Web of Science y Scopus. De esta manera, las reglas y estrategias de este multimillonario negocio pasan a hacer parte de nuestro naciente sistema de ciencia y tecnología reproduciendo un modelo al cual el Ministerio de Ciencias y Tecnología quiere insertar las revistas colombianas de un plumazo y sin la más mínima consideración a las notables diferencias que hay entre nuestro sistema académico y los foráneos. Otros editores de revistas académicas, particularmente en el campo de las ciencias sociales y humanas, han venido expresando quejas similares desde hace algunos años, pero el resultado siempre ha sido el mismo: COLCIENCIAS permanece imperturbable ante el clamor de la comunidad científica del país, tal vez porque se ha vuelto norma ignorar las opiniones de los interesados cuando no repiten, como borregos, las ideas de las autoridades administrativas. Ante tantas dificultades no es posible prever por cuanto tiempo más podamos mantener las publicaciones nacionales pero seguiremos trabajando con ahínco hasta que las condiciones y los múltiples (y a veces arbitrarios e innecesarios) requisitos lo permitan. 
Para esta entrega, y luego de un riguroso proceso de evaluación editorial, hemos seleccionado ocho artículos de investigación de distintos autores nacionales y extranjeros. El fascículo se abre con un trabajo de Luis Alejandro Murillo Lara, profesor de la Universidad Agustiniana, que lleva como título "Bodily Sensations and the varieties of spatial bodily awareness". En este escrito, Murillo examina la cuestión de si la conciencia de propiedades espaciales de nuestro cuerpo se obtiene mediante sensaciones corporales. El autor comienza por analizar nuestra actual comprensión de la dimensión espacial de las sensaciones corporales para luego introducir la noción de conocimiento no-observacional como principal objeción a la idea de que las sensaciones corporales son el medio por el cual somos conscientes de cualesquiera propiedades espaciales tiene nuestro cuerpo. En este artículo también se presentan dos importantes críticas filosóficas a dicha noción, así como una serie de hallazgos empíricos que podrían interpretarse como objeciones al conocimiento no-observacional. El autor concluye considerando una explicación alternativa a nuestra conciencia de propiedades especiales de nuestro cuerpo. Tras este interesante trabajo hemos incluido el artículo "Ni convencionalismo ni naturalismo. La justificación epistemológica de la verdad en Donald Davidson" de Jaime de Rosas Andreu quien está adscrito al Instituto de Filosofía de la Pontificia Universidad Católica de Chile. En este trabajo, de Rosas pretende defender la hipótesis según la cual la tesis davidsoniana del lenguaje, que presupone un conjunto de creencias y deseos compartidos, es un fenómeno cuasi-racional que proporciona las verdades $y$, a partir de ellas, permite deducir otros pensamientos objetivos en el dominio de los valores. De acuerdo con la interpretación que hace de Rosas, esta tesis se explica mejor si admitimos que Davidson concibe que el pensamiento y el lenguaje son previos a la convención, por lo que, necesariamente, surge el planteamiento de que esta teoría comprende intrínsecamente al ser humano como un ser pensante; esto es, un ser que goza de la inteligencia, de la capacidad de entender y comprender, aunque se encuentre desprovisto de contenido, lo cual implica negar toda forma de naturalismo que presuponga contenidos de creencias y deseos innatos.

Nuestro fascículo prosigue con el trabajo "Notas sobre el realismo selectivo y sus respuestas a los problemas del realismo científico" del profesor Benedicto Acosta de la Universidad de Salamanca. En este artículo, Acosta busca presentar brevemente tres corrientes del realismo selectivo en su relación con el realismo científico en 
general. Se trata del realismo estructural, el explicacionismo y el realismo de entidades. El autor comienza por definir el realismo filosófico y caracterizar el realismo científico y el realismo selectivo. La exposición parte de la hipótesis de que la principal virtud del selectivismo es poder responder al problema de las entidades inobservables en ciencia y al problema de la metainducción histórica de las teorías, rasgo que las conecta con otras propuestas realistas. Acosta corrobora esta hipótesis en los apartados dedicados a estas corrientes, los cuales presentan una misma estructura: primero se expone la respuesta que dan al problema de las entidades, seguida por la respuesta al problema teórico que implica el argumento de la metainducción. Tras este trabajo analítico, el autor desarrolla también algunas críticas abiertas a cada corriente. A continuación aparece un trabajo del profesor Carlos Emilio García, investigador de la Universidad de Caldas y de la Universidad de Manizales que se titula "Principales planteamientos epistemológicos en el debate Lee, Macintosh, Mattessich" artículo en el cual se examinan los planteamientos epistemológicos más destacados de un debate iniciado por Thomas Lee (2006) en el cual dicho autor formuló algunas críticas a la propuesta que hizo el FASB en 2002, para formular estándares contables basados en principios (ECBP) y planteó algunas tesis sobre ciertos problemas estrictamente epistemológicos. En particular, Lee se ocupó del realismo, la naturaleza de los hechos contables, la noción de "fidelidad representacional" y los enfoques epistemológicos que considera más propicios para iluminar las actividades teórico-prácticas de la contabilidad. García tuvo en cuenta para el análisis las contribuciones, argumentos y contraargumentos de Lee, Macintosh y Mattessich. Tras una presentación de sus principales planteamientos, el autor hace un balance de la discusión y analiza los méritos de los argumentos de cada uno de ellos. García concluye que, desde una perspectiva epistemológica, las tesis de Mattessich están mejor informadas y se apoyan en argumentos más fuertes y mejor articulados sobre aspectos como la naturaleza de la relación entre la teoría contable y los hechos de los que se ocupa, la función que cumple la información contable, sus principales características, la noción de "fidelidad representacional" y el carácter referencial de los conceptos contables.

Tras estos trabajos en el campo de la epistemología hemos incluido un artículo del profesor Julián David Bohórquez-Carvajal (Pontificia Universidad Javeriana, Bogotá) titulado “De la ciudad enferma. Platón 
e Hipócrates". En este trabajo, que podría clasificarse en el campo de la historia de la ciencia, Bohórquez-Carvajal explora la influencia de los Tratados Hipocráticos en la República de Platón, con énfasis en el papel de nociones provenientes de la llamada teoría humoral de la enfermedad. El autor comienza por analizar la importancia de los conceptos de "ciudad inflamada" y "sedición" (stasis) en el texto del filósofo ateniense, y sus relaciones con la ciencia médica de su tiempo. Luego, señala el papel de la dietética hipocrática en algunos argumentos consignados en la República, para pasar a abordar la lectura filosófica, presente en esta obra, del principio médico conocido como "la curación por lo semejante". Finalmente, Bohórquez-Carvajal indaga sobre diversas analogías significativas entre las tesis de la escuela de Hipócrates, en relación con el tratamiento de las enfermedades, y la propuesta platónica de una "curación de la ciudad". A continuación aparece el artículo "Pedro Laín Entralgo, una visión filosófica del cuerpo: Yo soy mi cuerpo" de los profesores Jonny Alexander García Echeverri (Universidad Católica de Oriente), Conrado De Jesús Giraldo Zuluaga (Universidad Pontificia Bolivariana) y Nicolás Duque Naranjo (Universidad Pontificia Bolivariana). En este trabajo los autores explican que decir "yo soy mi cuerpo" implica ampliar la apuesta filosófica y antropológica que hace Laín, en la cual se refleja el compromiso del ser humano con su situación vital; es tener conciencia del aquí y el ahora. Los autores dejan claro que en este tratado se hace evidente la influencia de la propuesta de Ortega y Gasset al decir "Yo soy yo y mi circunstancia, y si no la salvo a ella no me salvo yo" (2004, p. 757), a su vez, se adentran en los planteamientos filosóficos de Julián Marías Aguilera desde los cuales se asume al ser humano como un proyecto futurizo que necesita encarnarse en su propia vida, para crear otra realidad que lo salve a través de la historia.

Para cerrar este fascículo hemos escogido dos trabajos en el área de la estética. El primero de ellos se titula "La imagen estética en el horizonte de la ética del amor" de autoría del profesor Víctor Francisco Casallo Mesías adscrito a la Universidad Antonio Ruiz de Montoya en Perú. En este trabajo, Casallo analiza fenomenológicamente la dimensión valorativa en la contemplación de la imagen estética para mostrar cómo enriquece la apertura del yo al mundo y puede orientarlo al llamado a la renovación ético-cultural propuesta por Husserl como misión de la filosofía. El autor sitúa este llamado en el horizonte de la ética husserliana de los valores absolutos del amor, en la cual la maduración ética se entiende como un salir de sí mismo hacia el bien del otro en tanto otro. Así mismo, explica 
que la fenomenología de la experiencia de la imagen estética explicita su dimensión axiológica y cómo, a partir de ella, es posible acceder a otros mundos de sentido. Casallo sostiene que este enriquecimiento estético puede facilitar o suscitar una mirada crítica renovada ante el propio mundo circundante, la cual es condición para el despertar a la autorresponsabilidad última requerido por la fenomenología. De acuerdo con el autor, esta apreciación fenomenológica de la imagen estética puede contribuir con una autocomprensión más profunda de una formación ética que aspire a responder a las crisis culturales y políticas contemporáneas. Nuestra entrega se cierra con el artículo de "Consideraciones en torno al proceso de resimbolización en los márgenes de la estética reciente" del investigador español de la Universidad Complutense de Madrid Guillermo Aguirre. En este trabajo Aguirre parte de la sustitución histórica de una cosmovisión trascendente, cuyo símbolo mayor es la cruz, por otra inmanente que encuentra en la esfera su imagen de totalidad. El autor se propone presentar, con el ejemplo de modelos estéticos, el sentido latente de esta traslación. Aguirre se apoya, metodológicamente, en fundamentos hermenéuticos relativos a la función del símbolo y concluye que, tras un periodo de proliferación de perspectivismos y de necesaria relativización, actualmente asistimos a un momento de reorganización simbólica por vía de un monismo-trascendental.

Esperamos que este fascículo sea del agrado e interés de nuestros lectores habituales, de los autores y de los revisores. Agradecemos a todos aquellos que ha apoyado incondicionalmente nuestro proyecto editorial $y$, sobre todo, a quienes con su esfuerzo e interés mantienen vivas estas páginas. Como ya es habitual, invitamos a todos los interesados en la revista a expresar sus comentarios y sugerencias mediante el correo institucional de la revista. Reciban un cordial saludo y muchas gracias por seguirnos.

\section{Carlos Emilio García Duque Profesor titular Departamento de Filosofía Universidad de Caldas}

\section{Como citar:}

García Duque, C.E. "Presentación Editorial". Discusiones Filosóficas. jul.-dic. 2020: 7-11. https://doi.org/10.17151/difil.2020.21.37.1 